\title{
Possibilidades e desafios para a formação permanente de educadores dos anos iniciais: uma revisão de literatura
}

Sabrina Gonçalves Marques Sab marques@hotmail.com orcid.org/0000-0003-1820-5699 (UFSM), Santa Maria, RS, Brasil.

Cristiane Muenchen crismuenchen@yahoo.com.br orcid.org/0000-0003-3144-0933 Universidade Federal de Santa Maria (UFSM), Santa Maria, RS, Brasil.

\section{RESUMO}

A investigação aqui apresentada é parte de uma pesquisa de mestrado, que teve como um de seus objetivos específicos investigar elementos teóricos e metodológicos que contribuem para construção de processos formativos de educadores atuantes nos anos iniciais do Ensino Fundamental. Parte-se da compreensão de que o ensino de Ciências nos anos iniciais enfrenta alguns desafios e que a oferta de formação permanente, balizada nos referenciais da articulação Freire-CTS, constitui uma alternativa para a superação desses obstáculos. Dessa forma, foi realizada uma investigação nas atas das cinco últimas edições do ENPEC e do SNEF buscando identificar pesquisas que tratassem de processos formativos desenvolvidos com professores dos anos iniciais do Ensino Fundamental. Dezesseis trabalhos foram selecionados, a partir das palavras-chave "Ciência Tecnologia Sociedade" "Paulo Freire" e "Alfabetização Científica" e, analisados de acordo com as etapas da Análise Textual Discursiva. Os resultados indicam elementos como: momentos de estudos teóricos, discussões sobre currículo e epistemologia, a formação a partir de um tema, exercícios reflexivos, dentre outros aspectos, como possibilidades para construção das formações. Outros desafios que se apresentam para os formadores são o fortalecimento do trabalho coletivo, a transformação do fazer pedagógico em práxis e transformação das concepções sobre o papel do ensino de Ciências e sobre o currículo. Os resultados obtidos podem contribuir para construção de processos formativos que busquem a superação de desafios encontrados no ensino de Ciências nos anos iniciais. Contudo, defende-se uma perspectiva de formação permanente com vistas à superação de desafios que envolvem mudanças profundas de concepções e do fazer pedagógico dos educadores.

PALAVRAS-CHAVE: Ensino de Ciências. Formação Permanente. Anos iniciais. Articulação Freire-CTS. 


\section{O ENSINO DE CIÊNCIAS NOS ANOS INICIAIS DO ENSINO FUNDAMENTAL}

Quando se pensa nas características dos anos iniciais do Ensino Fundamental $(\mathrm{EF})$, logo vem à mente alfabetização, leitura, escrita, inserção da matemática, como se o currículo dos anos iniciais fosse limitado a poucos elementos, com ênfase, especialmente nos dois primeiros anos, no português (leitura e escrita) e na matemática. Pouco se pensa sobre o ensino de outras áreas do conhecimento nos anos iniciais do EF, como por exemplo, no ensino de Ciências nos primeiros anos de escolarização.

Desde os Parâmetros Curriculares Nacionais (PCNs) (BRASIL, 1997) o ensino de Ciências é parte significativa da organização curricular proposta pelos documentos oficiais da educação. Nos PCNs é marcante a busca pela formação do aluno para exercício da cidadania, com desenvolvimento do pensamento crítico e como questionador da realidade (BRASIL, 1997). As Ciências da Natureza no EF, nos PCNs, colaborariam com esses objetivos por meio do desenvolvimento de competências que permitiriam ao aluno compreender o mundo e utilizar os conhecimentos de natureza científica e tecnológica para a atuação cidadã (BRASIL, 1997). Ainda, de acordo com o mesmo documento, a seleção dos conteúdos necessita observar a relevância social e cultural, proporcionando aos alunos a construção da compreensão sobre o seu cotidiano, "as relações entre o homem e a natureza mediadas pela tecnologia, superando interpretações ingênuas sobre a realidade a sua volta" (BRASIL, 1997). Os PCNs também destacam a necessidade de tratamento interdisciplinar dos conteúdos, evidenciando isso em sua organização por blocos temáticos e nos temas transversais (BRASIL, 1997).

Atualmente, a Base Nacional Comum Curricular (BNCC) (BRASIL, 2017) reforça as contribuições do ensino de Ciências nos anos iniciais do EF para a formação da cidadania dos educandos e, com isso, sua inserção desde os anos iniciais da escolarização. Como destaca o documento, os educandos possuem conhecimentos construídos a partir de suas vivências anteriores à escola. A BNCC propõe, dessa forma, que esses conhecimentos sejam valorizados e mobilizados, constituindo o ponto de partida para a construção dos conhecimentos sistematizados de Ciências (BRASIL, 2017).

Também, a BNCC destaca que os alunos necessitam desenvolver, ao longo do $\mathrm{EF}$, oito competências correspondentes a área de Ciências da Natureza (BRASIL, 2017), que buscam um ensino voltado às ciências como ferramenta importante para compreensão dos contextos aos quais os alunos pertencem, com forte apelo à discussão de temáticas científico-tecnológicas e consequências do desenvolvimento da CT e as potencialidades do uso dos conhecimentos de Ciência e Tecnologia para proposição de soluções de problemas que atingem a sociedade como um todo.

Delizoicov, Angotti e Pernambuco (2011) destacam que a relação entre Ciência e Tecnologia e a forte presença desta última no cotidiano dos estudantes tornam urgente à inserção no currículo escolar de discussões acerca da relação entre Ciência e Tecnologia e, também, seus impactos sociais. Para os autores: 
transformador, de modo que garanta uma visão abrangente, quer dos processos, quer dos produtos - a conceituação envolvida nos modelos e teorias - que mais significativamente se mostrem relevantes e pertinentes para uma inclusão curricular. (DELIZOICOV; ANGOTTI; PERNAMBUCO, 2011, p. 69).

Viecheneski e Carletto (2013, p. 214), apoiados em vários autores, sinalizam que "democratizar o acesso aos conhecimentos (científicos e tecnológicos) tornou-se primordial para que os sujeitos possam compreender melhor o mundo, realizar escolhas conscientes e intervir responsavelmente no meio em que vivem". Para os autores citados, o ensino de Ciências assume um papel muito importante, visto que busca a promoção da cidadania.

Ainda, sobre a importância da educação científica estar presente desde os anos iniciais do EF, Rosa, Perez e Drum (2007, p. 359) sinalizam que "a conscientização sobre a necessidade do respeito e da valorização da natureza, o caráter provisório do conhecimento, a necessidade de participação consciente na tomada de decisões em torno dos problemas sociais" são indicadores da necessidade de incorporação da educação científica ao ensino de Ciências. Os mesmos autores destacam que a abordagem de conceitos científicos pode fazer parte do planejamento dos professores dos anos iniciais, visto que podem se constituir ferramentas para aproximação entre o ensino escolar e o contexto dos educandos.

Para Lima e Maués (2006), entretanto, o ensino de Ciências nos anos iniciais não deve estar preso ao ensino de conceitos científicos. As autoras compreendem que os conteúdos procedimentais e atitudinais são relevantes nesta etapa do ensino. Apoiadas em Vygotsky, as autoras defendem que o professor nessa fase é um companheiro de aprendizagens. Por isso são igualmente necessários conhecimentos sobre a aprendizagem das crianças e sobre os mecanismos pelos quais os conceitos cotidianos avançam em direção aos conceitos científicos. Assim, "papel que a professora exerce no desenvolvimento da criança é justamente o de forçar a ascendência dos conceitos cotidianos, de mediar o processo que vai abrindo caminho para a posse dos conceitos científicos" (LIMA; MAUÉS, 2006, p. 170). Rosa, Perez e Drum (2007) também argumentam nesse sentido, pois, entendem que, mais do que a precisão da conceituação científica, é importante que as crianças convivam com a linguagem das Ciências da Natureza e se apropriem aos poucos do pensamento científico como forma de compreender o mundo a sua volta.

Partindo da compreensão de que o conhecimento científico escolar busca contribuir, de forma crítica, para a leitura do mundo dos educandos, defende-se, em concordância com Viecheneski, Lorenzetti e Carletto (2012) que o ensino de Ciências nos anos iniciais tem o papel de iniciar o processo de Alfabetização Científica e Tecnológica (ACT) dos estudantes e que a ACT inicia-se na escola, algo que contudo, é um processo vitalício.

Embora na legislação e na literatura da área o ensino de Ciências nos anos iniciais pareça já estar bem consolidado, na prática parece passar por alguns percalços sinalizados por pesquisadores (VIECHENESKI; CARLETTO, 2013; ROSA; PEREZ; DRUM, 2007): a fragmentação curricular já nos anos iniciais em que o planejamento das aulas e a organização dos tempos de atividades é realizada por um único professor ou poucos professores; a ausência de aulas de Ciências em 
alguns planejamentos (ROSA; PEREZ; DRUM, 2007; CARVALHO; MARTINS, 2009; EIRAS; MENEZES, 2015) ou a repetição de práticas por longos anos, como a experiência de germinação a partir do feijão no algodão, vivenciada pela maioria dos alunos nas últimas décadas; concepções reducionistas acerca da natureza da ciência e da importância dos conhecimentos científicos; todos esses fatores apontam para a necessidade de reestruturação dos currículos dos cursos de formação inicial de professores que atuam nos anos inicias do EF e para a necessidade de oferta de formações permanentes para estes educadores, pois, como sinalizam Abreu, Bejarano e Carvalho $(2011$, p. 2) "não se ensina o que não se sabe".

Somados aos fatores listados, não se pode deixar de considerar também que, “infelizmente, mantém-se um ensino 'precário' com professores que enfrentam nas escolas problemas de sobrecarga, falta de recursos e de determinações que devem seguir, sobre as quais não foram ouvidos" (KRASILCHIK, 2000, p. 87). A afirmação de Krasilchik continua atual apesar de ter sido formulada há duas décadas, já que as condições de trabalho dos professores seguem praticamente inalteradas em alguns lugares do país. Todos esses fatores colaboram direta ou indiretamente para que o ensino de Ciências nos anos iniciais do EF, muitas vezes, não esteja na lista de prioridades dos educadores e da gestão escolar.

Dessa forma, torna-se urgente buscar alternativas para enfrentamento dos problemas presentes no ensino de Ciências nos anos iniciais. Entende-se como uma alternativa para superação da fragmentação curricular presente nesta etapa da educação básica e para contemplar objetivos presentes nos documentos oficiais como relação dos conteúdos com o contexto, a discussão as relações entre ciência, tecnologia, sociedade e, a relação do ser humano com o meio ambiente, a construção do currículo a partir da perspectiva da Abordagem Temática (AT) (PIERSON, 1997; DELIZOICOV; ANGOTTI; PERNAMBUCO, 2011; SCHNEIDER et al., 2014), em especial, da AT via Articulação Freire-CTS (AULER; DELIZOICOV, 2006; CENTA; MUENCHEN, 2016).

A AT consiste em uma perspectiva de reorientação curricular em que os temas são os elementos centrais e os conteúdos específicos das distintas áreas do conhecimento contribuem para sua compreensão. Dessa forma, o conteúdo é subordinado ao tema. (DELIZOICOV; ANGOTTI; PERNAMBUCO, 2011). Dentro do espectro da AT pode-se distinguir diferentes modalidades (KLEIN et al, 2019) que diferem entre si quanto aos tipos de temas e os processos de escolha destes, sendo uma dessas modalidades a AT via articulação Freire-CTS (AULER; DELIZOICOV, 2006; AULER; DELIZOICOV, 2015).

A articulação Freire-CTS consiste no diálogo entre os referenciais da Educação CTS e da Abordagem Temática Freireana (ATF) e está fundamentada em três elementos principais: a busca por currículos temáticos, a interdisciplinaridade e a construção de uma cultura de participação em processos decisórios (AULER, 2011). Dessa forma, os temas na articulação Freire-CTS são oriundos da realidade dos educandos e são obtidos por meio de processos de busca pelo tema gerador, dentre eles os Três Momentos Pedagógicos como estruturantes de currículos (MUENCHEN; DELIZOICOV, 2012) e as cinco etapas de Investigação Temática propostas por Delizoicov (1991). Nesses temas, a componente científico-tecnológica é fortemente trabalhada e busca-se a 
construção de uma cultura de participação em contraposição a cultura do silêncio.

A fim de aproximar a perspectiva da AT ou da AT via articulação Freire-CTS das salas de aula dos anos iniciais, buscando a superação algumas lacunas presentes no ensino de Ciências nessa etapa, compreende-se que é necessário proporcionar aos educadores formações que os instrumentalizem e busquem a transformação do seu fazer pedagógico.

Cabe salientar que se defende a perspectiva de formação permanente de professores, presente na concepção freireana de educação. A formação permanente fundamenta-se na ideia de inacabamento do ser humano, basilar do pensamento de Freire (CENTA, 2015; SANTIAGO; BATISTA NETO, 2011). Os educadores, assim como os educandos, são seres inacabados e necessitam estar conscientes do seu inacabamento. Dessa forma, a educação dialógica e libertadora necessita respeitar a "vocação ontológica de ser mais" dos educadores e educandos, não aceitando a condição atual como permanente e inexorável, mas passível de mudança (FREIRE, 2005; FREIRE, 2014). Defender a formação permanente consiste em compreender que os educadores, porque inacabados, necessitam estar em constante formação, uma formação voltada ao seu contexto, a partir de sua realidade e da realidade de seus educandos.

Partindo da compreensão da necessidade de repensar a oferta e a estrutura da formação dos professores que atuam nos anos iniciais, o presente trabalho, parte de uma dissertação de mestrado em Ensino de Física, onde apresenta-se os resultados encontrados a partir de um dos objetivos específicos da pesquisa, que consistia em investigar elementos teóricos e metodológicos que contribuem para construção de processos formativos para educadores atuantes nos anos iniciais do EF. Os elementos encontrados na investigação contribuíram para construção de um processo formativo balizado na articulação Freire-CTS que foi desenvolvido com educadores dos anos iniciais, de uma escola pública municipal do interior do Rio Grande do Sul, no período de Agosto de 2018 a Abril de 2019.

\section{A INVESTIGAÇÃO CONDUZIDA}

A investigação dos elementos teóricos e metodológicos foi realizada em trabalhos apresentados no Simpósio Nacional de Ensino de Física (SNEF) e Encontro Nacional de Pesquisa em Educação em Ciências (ENPEC), no intervalo de 2008 a 2018, sendo contempladas cinco edições de cada evento neste período. A escolha por esses eventos foi devido a sua amplitude de alcance, indo desde trabalhos realizados por pesquisadores de universidades até trabalhos desenvolvidos por licenciandos e professores da educação básica.

O SNEF é um simpósio bienal promovido pela divisão de Ensino da Sociedade Brasileira de Física (SBF) desde 1970. Caracteriza-se por reunir professores da educação básica, licenciandos e pesquisadores do ensino de Física e áreas afins que socializam pesquisas e práticas realizadas em seus contextos formativos e de trabalho.

O ENPEC é um encontro bienal organizado pela Associação Brasileira de comunidade de pesquisa em Educação e ensino de Ciências e áreas afins. 
A partir das atas dos eventos realizados nos anos de 2009, 2011, 2013, 2015 e 2017, foi construída uma biblioteca no software Mendeley, que possibilitou a busca de palavras-chave nos títulos, resumos e corpo dos textos. Inicialmente, foram selecionados trabalhos que continham as expressões "Alfabetização Científica", "Ciência Tecnologia Sociedade" e "Paulo Freire", sendo essa a primeira etapa da busca. A seleção das palavras-chave "Ciência Tecnologia Sociedade" e "Paulo Freire" ocorreu para localização de trabalhos que compartilhassem aspectos teóricos com a articulação Freire-CTS, recorte teórico que balizou a pesquisa de mestrado. A palavra-chave "Alfabetização Científica" foi selecionada por ser apontada por alguns autores como objetivo geral da Educação CTS. Além disso, alguns documentos oficiais apresentam a AC como um dos objetivos do ensino de Ciências nos anos iniciais e, também, por estar vinculada a muitos trabalhos desenvolvidos nos anos iniciais.

A partir da primeira etapa foram formados três grandes grupos de trabalhos que passaram por uma segunda etapa de busca para que fossem selecionados os que tratavam sobre pesquisas nos anos iniciais do EF. Por fim, na terceira etapa da busca foram selecionadas pesquisas que tratavam de processos formativos realizados com professores atuantes de 10 a 5o ano do EF. Os números de trabalhos correspondentes a cada etapa de seleção estão relacionados no quadro abaixo:

Quadro 1 - Delimitação do corpus de análise da revisão bibliográfica

\begin{tabular}{|c|c|c|c|c|c|c|}
\hline Evento & $\begin{array}{c}\text { AC nos } \\
\text { anos } \\
\text { Iniciais } \\
\text { (2a } \\
\text { etapa) }\end{array}$ & $\begin{array}{c}\text { Processos } \\
\text { formativos } \\
\text { em AC } \\
\text { (3a etapa) }\end{array}$ & $\begin{array}{c}\text { CTS nos } \\
\text { anos } \\
\text { iniciais } \\
\text { (2a } \\
\text { etapa) }\end{array}$ & $\begin{array}{c}\text { Processos } \\
\text { formativos } \\
\text { em CTS } \\
\text { (3a etapa) }\end{array}$ & $\begin{array}{c}\text { Paulo } \\
\text { Freire nos } \\
\text { anos } \\
\text { iniciais } \\
\text { (2a etapa) }\end{array}$ & $\begin{array}{c}\text { Processos } \\
\text { formativos } \\
\text { em Paulo } \\
\text { Freire } \\
\text { (3a etapa) }\end{array}$ \\
\hline $\begin{array}{c}\text { VII } \\
\text { ENPEC }\end{array}$ & 5 & 0 & 6 & 0 & 9 & 2 \\
\hline $\begin{array}{c}\text { VIII } \\
\text { ENPEC }\end{array}$ & 19 & 1 & 4 & 0 & 8 & 1 \\
\hline $\begin{array}{c}\text { IX } \\
\text { ENPEC }\end{array}$ & 17 & 1 & 8 & 2 & 9 & 0 \\
\hline $\begin{array}{c}\text { X } \\
\text { ENPEC }\end{array}$ & 23 & 4 & 13 & 1 & 17 & 3 \\
\hline $\begin{array}{c}\text { XI } \\
\text { ENPEC }\end{array}$ & 39 & 0 & 22 & 0 & 20 & 0 \\
\hline $\begin{array}{c}\text { XVIII } \\
\text { SNEF }\end{array}$ & 2 & 2 & 2 & 1 & 1 & 1 \\
\hline $\begin{array}{c}\text { XIX } \\
\text { SNEF }\end{array}$ & 4 & 0 & 3 & 0 & 0 & 0 \\
\hline $\begin{array}{c}\text { XX } \\
\text { SNEF }\end{array}$ & 6 & 1 & 3 & 0 & 4 & 1 \\
\hline $\begin{array}{c}\text { XXI } \\
\text { SNEF }\end{array}$ & 8 & 2 & 1 & 0 & 3 & 0 \\
\hline $\begin{array}{c}\text { XXII } \\
\text { SNEF }\end{array}$ & 10 & 0 & 2 & 0 & 3 & 1 \\
\hline Total & 133 & 11 & 64 & 4 & 74 & 9 \\
\hline
\end{tabular}

Fonte: Autoria própria (2019). 
É importante salientar que alguns trabalhos estavam presentes em mais de um grupo porque continham mais de uma das palavras-chave utilizadas para seleção, por exemplo, continham as palavras-chave "Alfabetização Científica e Tecnológica" e, também, as palavras-chave "Ciência Tecnologia Sociedade". Assim, após identificação dos trabalhos duplicados, restaram 19 trabalhos que foram lidos na íntegra para que fosse possível identificar se todos tratavam de processos formativos voltados aos professores dos anos iniciais. Foram considerados tanto projetos em desenvolvimento, quanto em execução e concluídos. Dos 19 trabalhos selecionados, 3 foram desconsiderados por não atenderem aos requisitos e, ao final restaram 16 trabalhos que compuseram o corpus de análise descrito no quadro a seguir:

Quadro 2-Corpus de análise

\begin{tabular}{|c|c|}
\hline Legenda & Referência \\
\hline $\mathrm{T} 1$ & $\begin{array}{l}\text { CARVALHO, L. S.; MARTINS, A. F. História da Ciência na formação } \\
\text { de professores das séries iniciais: uma proposta com quadrinhos } \\
\text { In: VII Encontro Nacional de Pesquisa em Educação em Ciências, } \\
\text { 2009. Florianópolis, Anais... Florianópolis: } 2009 \text {. }\end{array}$ \\
\hline $\mathrm{T} 2$ & $\begin{array}{l}\text { CECCON, S.; COMPIANI, M.; HOEFFEL, J. L. M. Estudo de Caso no } \\
\text { Programa de Educação Ambiental Fruto da Terra: } \\
\text { contextualização e não disciplinarização. In: VII Encontro } \\
\text { Nacional de Pesquisa em Educação em Ciências, } 2009 . \\
\text { Florianópolis, Anais... Florianópolis: } 2009 .\end{array}$ \\
\hline T3 & $\begin{array}{l}\text { ABREU, L. S.; BERJARANO, N.; CARVALHO, A. M. P. Professores de } \\
\text { Ciências no Ensino Fundamental I como aprendizes: um estudo } \\
\text { de caso. In: VIII Encontro Nacional de Pesquisa em Educação em } \\
\text { Ciências. 2011, Campinas. Anais... Campinas: } 2011 .\end{array}$ \\
\hline T4 & $\begin{array}{l}\text { SANTANA, L. N.; SALOMÃO, S. R. Formação continuada de } \\
\text { professores de ciências atuantes na EJA (Educação de Jovens e } \\
\text { Adultos): refletindo sobre a utilização de experimentos. In: VIII } \\
\text { Encontro Nacional de Pesquisa em Educação em Ciências. 2011, } \\
\text { Campinas. Anais... Campinas: } 2011 .\end{array}$ \\
\hline T5 & $\begin{array}{l}\text { SILVA, A. F. A. S.; MARCONDES, M. E. R. Concepções sobre } \\
\text { Ciência, Tecnologia e Sociedade de um grupo de professores de } \\
\text { séries iniciais. In: IX Encontro Nacional de Pesquisa em Educação } \\
\text { em Ciências. 2013, Águas de Lindóia. Anais... Águas de Lindóia: } \\
2013 .\end{array}$ \\
\hline T6 & $\begin{array}{l}\text { KAUARK, F. S.; ABREU, S. C. S. R.; ABREU, F. R. A Educação em } \\
\text { Ciências como mosaico da cidadania escolar. In: IX Encontro } \\
\text { Nacional de Pesquisa em Educação em Ciências. 2013, Águas de } \\
\text { Lindóia. Anais... Águas de Lindóia: 2013. }\end{array}$ \\
\hline T7 & $\begin{array}{c}\text { BRICCIA, V. CARVALHO, A. M. P. A formação de professores para } \\
\text { os anos iniciais: questões a relevar. In: X Encontro Nacional de } \\
\text { Pesquisa em Educação em Ciências. 2015, Águas de Lindóia. } \\
\text { Anais... Águas de Lindóia: } 2015 .\end{array}$ \\
\hline T8 & $\begin{array}{l}\text { GONZATTI, S. E. M.; GIONGO, I. M.; HERBER, J.; QUARTIERI, M. T. } \\
\text { Docência nos anos iniciais e a abordagem das Ciências Exatas em } \\
\text { uma perspectiva integradora. In: X Encontro Nacional de } \\
\text { Pesquisa em Educação em Ciências. 2015, Águas de Lindóia. } \\
\text { Anais... Águas de Lindóia: 2015. }\end{array}$ \\
\hline T9 & $\begin{array}{l}\text { EIRAS, W. C. S.; MENEZES, P. H. D. Capacitação e prática docente } \\
\text { no ensino de Ciências nos anos iniciais do Ensino Fundamental: } \\
\text { uma relação necessária. In: X Encontro Nacional de Pesquisa em }\end{array}$ \\
\hline
\end{tabular}




\begin{tabular}{|c|c|}
\hline Legenda & Referência \\
\hline & $\begin{array}{c}\text { Educação em Ciências. 2015, Águas de Lindóia. Anais... Águas de } \\
\text { Lindóia: } 2015 .\end{array}$ \\
\hline T10 & $\begin{array}{l}\text { PIZARRO, M. V.; JUNIOR, J. L. Alfabetização científica nos anos } \\
\text { iniciais: necessidades formativas, aprendizagens profissionais e a } \\
\text { Teoria do Agir Comunicativo como proposta de formação. In: X } \\
\text { Encontro Nacional de Pesquisa em Educação em Ciências. 2015, } \\
\text { Águas de Lindóia. Anais... Águas de Lindóia: } 2015 \text {. }\end{array}$ \\
\hline T11 & $\begin{array}{l}\text { NOVAIS, E. S. P.; et al. O processo de Redução Temática do Tema } \\
\text { Gerador “Para onde vai o lixo do meio rural de Iguaí/BA?”. In: X } \\
\text { Encontro Nacional de Pesquisa em Educação em Ciências. 2015, } \\
\text { Águas de Lindóia. Anais... Águas de Lindóia: } 2015 .\end{array}$ \\
\hline T12 & $\begin{array}{c}\text { HUGUENIN, J. A. O.; et al. Concepções alternativas entre } \\
\text { professores e normalistas: desafios para o ensino de ciências. In: } \\
\text { XVIII Simpósio Nacional de Ensino de Física. 2009, Vitória. Anais... } \\
\text { Vitória: } 2009 .\end{array}$ \\
\hline T13 & $\begin{array}{l}\text { SILVA, A. M. T. B.; METTRAU, M. B. Proposta de ensino de } \\
\text { ciências sob forma lúdica e criativa nas escolas. In: XVIII Simpósio } \\
\text { Nacional de Ensino de Física. 2009, Vitória. Anais... Vitória: } 2009 .\end{array}$ \\
\hline T14 & $\begin{array}{c}\text { BENTO, E. P.; BARROS, M. A. As Ciências Naturais nas séries } \\
\text { iniciais e o Enfoque CTS-A na formação continuada de } \\
\text { professores de Areia-PB. In: XVIII Simpósio Nacional de Ensino de } \\
\text { Física. 2009, Vitória. Anais... Vitória: } 2009 .\end{array}$ \\
\hline T15 & $\begin{array}{c}\text { FLORES, J. F.; FILHO, J. B. R. Ensino de Física e a pesquisa nas } \\
\text { séries iniciais: um estudo com luz e sombra. In: XXI Simpósio } \\
\text { Nacional de Ensino de Física. } 2015 \text {, Uberlândia. Anais... } \\
\text { Uberlândia: } 2015 .\end{array}$ \\
\hline T16 & $\begin{array}{l}\text { FONSECA, K. N.; et al. Contribuições da Física para a conservação } \\
\text { da carne vendida na feira do Bairro de Fátima em Itabuna/BA. In: } \\
\text { XXII Simpósio Nacional de Ensino de Física. 2017, São Carlos. } \\
\text { Anais... São Carlos: } 2017 .\end{array}$ \\
\hline
\end{tabular}

Fonte: Autoria própria (2019).

Os trabalhos foram analisados segundo a dinâmica da Análise Textual Discursiva (ATD) (MORAES; GALIAZZI, 2007) que consiste em um processo autoorganizado de análise que busca a construção de novas compreensões sobre o material de pesquisa por meio de um ciclo com três etapas: (1) unitarização, que consiste na desconstrução dos textos em fragmentos menores, chamados de unidades de significado que representam o fenômeno estudado; (2) categorização, que corresponde ao processo de agrupamento das unidades por meio de relações estabelecidas pelo pesquisador, à luz do referencial teórico; as categorias organizadas e articuladas ao referencial teórico são o novo emergente que corresponde às novas compreensões sobre o fenômeno estudado, que são sistematizadas em metatextos no momento da (3) comunicação.

O processo de desconstrução dos textos gerou 48 unidades de significado agrupadas em duas categorias, a priori: (1) Possibilidades para um processo formativo; (2) Desafios para a formação permanente. Para facilitar a leitura do texto, os fragmentos serão identificados pelo código do trabalho ao qual pertencem (conforme o quadro 2). 


\section{POSSIBILIDADES PARA UM PROCESSO FORMATIVO}

A partir da análise dos trabalhos foi possível identificar algumas possibilidades para um processo formativo, que contemplam aspectos teóricos e metodológicos e podem contribuir para a construção desse processo.

Há consenso, quase a totalidade dos trabalhos analisados, da necessidade de dedicar um tempo para estudos teóricos dos referenciais que balizam as abordagens e metodologias escolhidas para guiar os processos formativos.

Outro aspecto teórico a ser destacado é a presença de discussões de cunho epistemológico na formação proposta em T1. Os pesquisadores conduziram uma discussão acerca da natureza da ciência a partir da história da descoberta da circulação sanguínea, apresentando aos professores como se dá a produção do conhecimento científico. As compreensões acerca da natureza da ciência constituem elemento importante para problematização da concepção de neutralidade da Ciência (AULER; DELIZOICOV, 2001) presentes algumas vezes no pensamento de alguns professores. Para um ensino de Ciências com rigor científico é necessário descontruir visões equivocadas acerca da ciência e do trabalho científico e, nesse sentido, o estudo da epistemologia da ciência tem muito a contribuir.

T6 e T14 trazem dois elementos importantes para discussão em suas propostas de formação. Em T6, os autores defendem que uma formação continuada com viés crítico necessita contemplar discussões acerca do currículo. Esse ponto remete ao problema da fragmentação curricular nos anos iniciais, apresentado por pesquisadores. Marques e Hunsche (2017) destacam a necessidade de discussões acerca do currículo escolar, em especial das Ciências da Natureza, pois, em uma investigação acerca do currículo e da prática de Ciências nos anos iniciais de uma escola pública, perceberam que as educadoras consideram a fragmentação das disciplinas como a forma mais adequada para organizar o ensino e não percebem outras atividades, ricas em potencial interdisciplinar e de aprendizagem a partir do contexto, como parte do currículo escolar. As discussões curriculares podem ocorrer a partir do estudo de referenciais de reconfiguração curricular, como, por exemplo, a AT ou AT via articulação Freire-CTS, pois, para buscar um ensino de Ciências com vistas à conscientização para participação social é necessário discutir de que forma o currículo escolar está contribuindo para este objetivo e um ensino a partir da AT, implica necessariamente em discutir a organização do currículo escolar.

Como sinalizado acima, um aspecto importante é a discussão de aspectos teóricos. Contudo, a forma como os aspectos teóricos foram discutidos nos processos formativos analisados seguiu diferentes escolhas metodológicas. T1 e T13, por exemplo, dedicam um momento de discussão do referencial a partir de uma leitura prévia (T1) e, também, durante os encontros de formação (T13). Em T14, por exemplo, foram realizados cursos, oficinas e palestras, em horário de trabalho pedagógico coletivo, que possibilitaram aos professores momentos de construção de reflexões compartilhadas. A construção coletiva de conhecimentos sobre o referencial também foi destacada pelos formadores de T1. Em T3 os pesquisadores optaram pela realização de fóruns de formação para discussão teórico-metodológica. Em T11 o processo formativo aconteceu durante a busca por um Tema Gerador o que pode ser compreendido como um momento de estudo do referencial, pois, para realização da investigação da realidade é 
necessário que os educadores se apropriem de algum referencial balizado nos pressupostos freireanos como as cinco etapas da Investigação Temática propostas por Delizoicov (1991), ou as cinco etapas para a busca do Tema Gerador propostas por Silva (2004), os Três Momentos Pedagógicos como estruturantes de currículos (ARAÚJO; MUENCHEN, 2018).

Alguns formadores buscam conhecer, primeiramente, o que os professores já sabem a respeito do referencial teórico e começar a discussão partindo desse conhecimento. Em T5 (p. 6) os autores destacam um momento em que "foi promovida uma discussão sobre os conceitos Ciência, Tecnologia e Sociedade, bem como as inter-relações possíveis entre eles, buscando assim investigar quais os significados que os professores atribuíam a eles". T2, T4, T10 e T14 realizaram aplicações de questionários abertos e conversas que foram chamadas de diagnóstico do ensino de Ciências (T2) ou sondagem de conhecimentos dos professores (T4) que buscavam "mapear seus conhecimentos a respeito do referencial e da modalidade de educação na qual atuam e sobre formação continuada" (T4), também, para simples análise do perfil dos participantes (T14) ou para caracterização dos profissionais a fim de determinar a próxima fase dos projetos (T10). Embora os objetivos que direcionaram a escolha dos instrumentos para essa aproximação inicial tenham sido distintos para cada trabalho, os formadores compartilharam a necessidade de conhecer o contexto de atuação dos professores e suas práticas pedagógicas, para que os processos formativos sejam delineados de modo que possibilite a participação dos professores e que auxiliem na superação de dificuldades ou na conscientização desses educadores.

Alguns autores preferem seguir por uma abordagem expositiva do referencial teórico (T3), todavia, é necessário que se pense se esse tipo de abordagem está de acordo com o referencial que baliza a formação. Por exemplo, aqui defende-se uma perspectiva de formação permanente com o desenvolvimento de um processo formativo balizado na articulação Freire-CTS. Dessa forma, não é coerente adotar abordagens expositivas porque balizando-se no referencial freireano, o ato educativo deve ser pautado no diálogo, pois

\footnotetext{
Somente quem escuta paciente e criticamente o outro, fala com ele. Mesmo que, em certas condições, precise de falar a ele. O que jamais faz quem aprende a escutar para poder falar com é falar impositivamente. Até quando, necessariamente, fala contraposições ou concepções do outro, fala com ele como sujeito da escuta de sua fala crítica e não como objeto de seu discurso (FREIRE, 2014, p. 116).
}

Assim, defende-se que os educadores e as educadoras participantes do processo formativo não sejam objeto do discurso dos formadores, mas sim participantes dos diálogos durante esse processo.

A exemplificação foi uma estratégia adotada por T3 e T4 para ilustrar possibilidades de trabalho com os referenciais adotados. Essa pode ser uma forma de envolver os educadores participantes para que construam seus conhecimentos de forma ativa, contudo, a escolha de T14 parece mais alinhada com a perspectiva da articulação Freire-CTS. Os pesquisadores desenvolveram o processo formativo por meio da abordagem de um tema local no enfoque CTS-A. Como destacam os autores: 
comunidade local. Para tal, utilizamos como tema central O uso do açúcar como uma cultura de sustentabilidade uma vez que a região é conhecida pela produção em larga escala de aguardente e rapadura cuja matéria-prima é a cana-de-açúcar (T14, p. 2, grifo dos autores)

Os pesquisadores, a partir do contexto da comunidade escolar e de uma conversa prévia com os professores, selecionaram um tema da realidade local que poderia ser abordado por meio do enfoque CTS, o que está de acordo com o referencial, pois, nesse enfoque o tema pode ser escolhido pelos educadores.

Para auxiliar os professores a repensarem suas práticas, os pesquisadores/formadores utilizaram diferentes estratégias que guardavam relação com os referenciais teóricos adotados. Todos os trabalhos incluíam momentos em que os professores iam para sala de aula realizar atividades relacionadas aos processos formativos como, por exemplo, em T15 que os professores foram desafiados a realizarem atividades experimentais com seus alunos ou em T11, T14 e T16 que os educadores, envolvidos em processos de AT, desenvolviam em sala de aula os currículos gerados pela redução dos temas. Após esse momento, os trabalhos T2, T7, T8 e T10 destacam o retorno dos professores a respeito do desenvolvimento das atividades com seus alunos. Esse retorno tinha como objetivo a socialização dos resultados obtidos, proporcionando momentos de discussão e reflexão coletiva sobre a prática.

Em T15, alinhado com o referencial educar pela pesquisa (DEMO, 1997), os professores participantes foram desafiados pelos pesquisadores a implementarem atividades práticas sobre os conceitos de Física com seus alunos. Foi solicitado que, durante a aula dedicada à realização da atividade, os professores fizessem anotações sobre o que observavam dos alunos. Os pesquisadores defendem que essas anotações podem ajudar o professor a analisar suas compreensões de como as crianças aprendem e com isso perceberem a possibilidade de abordagem de outros conteúdos em suas aulas. Essa estratégia pode contribuir para superação do pensamento de que crianças não podem aprender conceitos científicos, pois, "a ciência desenvolvida nas séries iniciais não deverá se eximir de abordar conhecimentos de Física, por exemplo, se quiser um ensino que aproxime os conhecimentos científicos do mundo vivenciado pelos estudantes" (ROSA; PEREZ; DRUM, 2007, p.358). Como destacam Viecheneski e Carletto (2013, p. 217), nesta etapa da educação básica a preocupação com o ensino de Ciências é "mais da ordem dos conteúdos procedimentais e atitudinais do que conceituais propriamente dito".

T3 e T13 seguem pelo mesmo caminho, sinalizando a importância de o professor registrar suas observações e aprendizados. Os educandos sugerem a elaboração de relatórios e de diários como instrumentos para reflexão sobre a prática, acrescentando a necessidade de posterior socialização dessas aprendizagens para um momento coletivo de reflexão.

Os formadores de T14, balizados pela Educação CTS, realizaram a problematização do tema com os professores com objetivo de que além de estarem, nesse momento, no papel de educandos, pudessem realizar a problematização do tema posteriormente com seus alunos, tendo como referência a experiência que vivenciaram durante a formação.

Página | 421

Alinhados com a perspectiva temática que se defende, os trabalhos T11, T14 e T16 organizaram seus processos formativos a partir de temas. Dentre os 
trabalhos analisados, T11 e T16 são os que mais se aproximam ao processo formativo construído, pois, apresentam propostas de ATF desenvolvidas em processos formativos. Nesses trabalhos os professores participaram ativamente em cooperação com os pesquisadores no processo de IT e, após a obtenção do tema, na redução temática e no desenvolvimento de atividades para sala de aula. Em consonância com a ATF, os professores, como parte da comunidade, foram ativos durante todo processo. Em T11 os pesquisadores destacaram a participação dos professores em todas as etapas da IT. Como exemplo, destacase o momento da codificação em que "realizou-se a discussão da fala dos alunos e moradores em relação às hipóteses de situação limite, a partir da qual emergiram novos elementos, como a compreensão acrítica do problema e acomodação ao problema" (p. 4). Esses trabalhos sinalizam a importância de pensar formações que possibilitem aos professores o desenvolvimento de sua autonomia e o aproveitamento da sala de aula como espaço de pesquisa e desenvolvimento da prática. Considera-se que trabalhar a formação a partir da ATF constitui tanto aspecto teórico quanto metodológico.

Embora cada trabalho tenha um planejamento diferente, de acordo com o referencial adotado, todos apresentam elementos comuns como: aproximação inicial para conhecer o contexto de atuação dos professores e suas concepções sobre o ensino de Ciências e sobre o referencial adotado; estudo do referencial com os professores; momento de reconstrução da teoria na prática em que os educadores elaboram atividades práticas ou constroem um currículo; retomada das práticas implementadas a partir do estudo do referencial em momentos de socialização dos resultados e reflexão sobre a prática.

A análise dos trabalhos trouxe elementos importantes a serem considerados no delineamento de processos formativos, apontando formas de organização e discussões teóricas importantes, bem como dimensões práticas a serem valorizadas.

\section{DESAFIOS PARA PROPOSIÇÃO DE UM PROCESSO FORMATIVO}

A análise do corpus revelou diferentes possibilidades para um processo formativo. Contudo, além de possibilidades, os autores sinalizam alguns desafios a serem superados por pesquisadores e educadores que pensam a formação continuada ou permanente dos professores. T10 apresenta uma provocação em sua proposta, salientando que "nossa proposta de trabalho é romper com essa tradição de observar o que o professor faz, classificar como certo ou errado e falar por ele, como se ele não tivesse voz, opinião e argumentação sobre a finalidade de sua própria prática". Os pesquisadores questionam sobre o "uso" que a academia faz das escolas e dos professores, algumas vezes, sem ouvir o que já sabem a partir de suas experiências profissionais. $O$ alerta é pertinente e está alinhado com uma perspectiva dialógica e problematizadora de educação. Defende-se que os processos formativos tenham compromisso com o diálogo e com a práxis, intrínsecos ao olhar freireano sobre a educação. Ao pensar a formação buscando superar essa dicotomia entre a realidade do professor e o que lhe é apresentado pelos formadores é possível ainda avançar para discussões teóricas que tenham reflexo na prática do professor, pois, como salientam os formadores de T1, uma discussão teórica isolada pode ser limitada e limitante. 
Entretanto, como destacam os pesquisadores de T2, transformar concepções é um desafio. Ao propor um processo formativo balizado na articulação FreireCTS busca-se a transformação de concepções acerca da relação entre Ciência Tecnologia Sociedade, sejam concepções ingênuas sobre a ciência, como por exemplo a crença na neutralidade científica, seja a crença no determinismo tecnológico, seja o endosso a tecnocracia que dificulta "o despertar de uma cultura de participação" (CENTA; MUENCHEN, 2016).

T5 (p. 8) propõe que

"A formação de professores, tanto inicial quanto continuada precisa promover exercícios reflexivos que favoreçam a superação de concepções inadequadas, com vistas à uma formação profissional que propicie saberes necessários a uma atuação docente mais consciente e crítica".

Ainda, T1, mais alinhado com os referenciais aqui adotados, sinaliza que os processos formativos necessitam transformar o fazer pedagógico em práxis, pois, dessa forma é possível atingir a "formação de profissionais críticos e autônomos" (T2).

Para realizar um exercício de transformação do fazer pedagógico em práxis é necessário que o diálogo seja central nas formações. T4 e T10 destacam a necessidade de promover diálogos no coletivo dos educadores e pesquisadores, pois, este é um importante espaço de reflexão sobre suas práticas e sobre o processo formativo em si.

Por fim, T1 e T8 defendem que a formação no ambiente de trabalho dos professores e a participação da gestão escolar no processo formativo podem contribuir para o fortalecimento do trabalho coletivo e para avaliação dos impactos da formação nas diferentes áreas do espaço escolar.

Essa categoria auxiliou para repensar o papel do diálogo no processo formativo, sendo esse balizador das ações com vistas a proporcionar um espaço para que o fazer pedagógico transforme-se em práxis.

A análise dos trabalhos apontou alguns aspectos ligados a possibilidades e desafios a serem considerados na construção de processos formativos. A figura 1 apresenta uma síntese das discussões dessas categorias. 
Figura 1 - Síntese das discussões

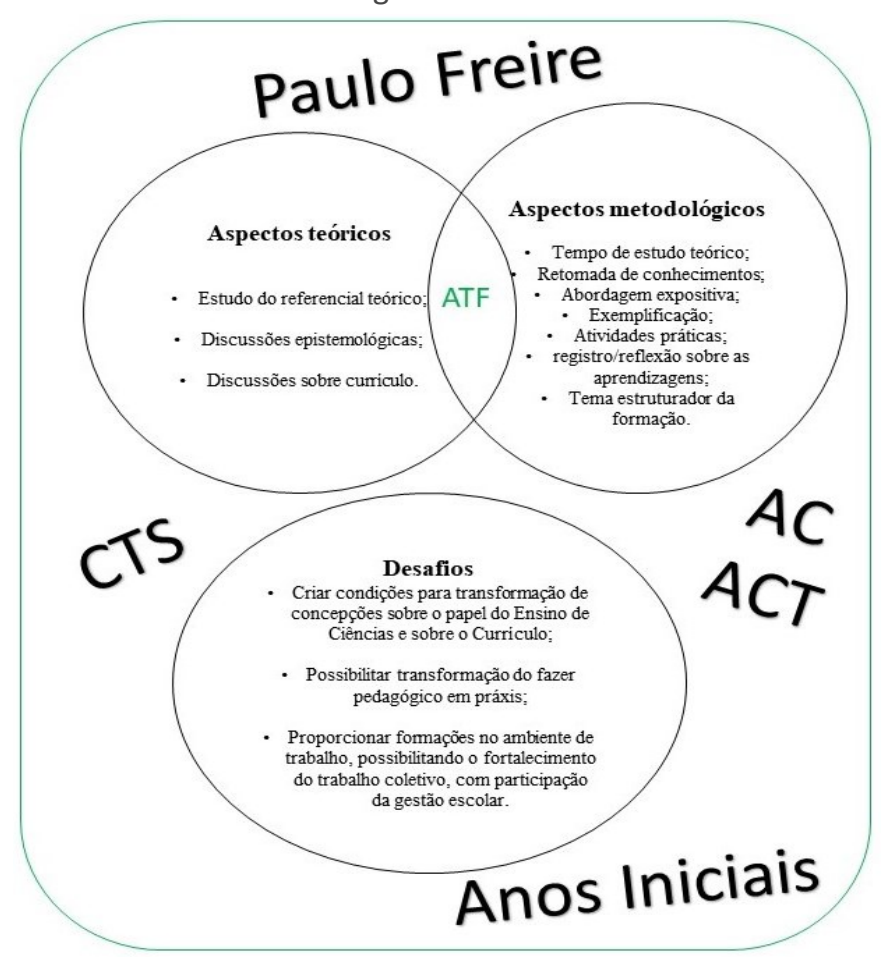

Fonte: Autoria própria (2019).

\section{CONSIDERAÇÕES FINAIS}

A investigação apresentada resulta da compreensão de que são necessários processos formativos que pensem no educador que atua nos anos iniciais do EF para que lacunas presentes no ensino de Ciências, nesta etapa da educação básica, sejam minimizadas e/ou superadas. Assim, foi realizada uma investigação em trabalhos publicados nos ENPECs e nos SNEFs para identificar pesquisas que tratassem de processos formativos realizados com professores dos anos iniciais do EF e que estivessem alinhados com a perspectiva da articulação Freire-CTS.

Os resultados indicam três elementos teóricos que necessitam fazer parte da construção de processos formativos para esse público: discussões teóricas, discussões acerca da epistemologia da ciência e sobre o currículo. Estes aspectos estão alinhados com a perspectiva da articulação Freire-CTS, porque, como esta configura uma modalidade de AT, faz-se necessário discutir a construção curricular. Da mesma forma, a Educação CTS, presente na articulação, aponta para necessidade de discussões acerca da natureza da ciência, em especial, a problematização acerca da não neutralidade da ciência e do trabalho científico.

As pesquisas também apresentam elementos metodológicos para organização das atividades durante os encontros de formação: tempo para estudo teórico, abordagem expositiva, exemplificação, registro e reflexão sobre as atividades, retomada de conhecimentos, atividades práticas e estruturação da formação a partir de um tema, alinhada com trabalhos balizados na AT. Destes aspectos, apenas a abordagem expositiva não converge com a articulação, pois, por se tratar de um trabalho balizado na educação dialógica e libertadora de Freire, o diálogo é elemento central. 
Ainda, os autores apresentam alguns desafios a serem superados por formadores: delinear processos formativos alinhados com a realidade dos educadores, partindo de suas necessidades formativas e que tragam contribuições para a escola, buscando superar a cultura de "uso" desta por parte da academia; possibilitar a transformação de concepções de acordo com o referencial adotado; buscar a transformação do fazer pedagógico em práxis; delinear formações possíveis de serem realizadas no horário de trabalho dos professores e que ocorram em seu ambiente de trabalho, favorecendo o trabalho coletivo e a participação da gestão escolar. Considera-se que um processo formativo balizado na articulação Freire-CTS pode contribuir para superação dos desafios, pois, a transformação do fazer pedagógico em práxis é parte importante do pensamento educacional freireano. Da mesma forma, a participação de toda a comunidade escolar no processo educativo é um dos princípios deste pensamento, em especial com a valorização do diálogo com a comunidade escolar na busca pelos Temas Geradores. Sendo o diálogo valorizado, torna-se possível superar a cultura de "uso" das escolas.

Contudo, salienta-se que os desafios apresentados pelos formadores consistem em mudanças profundas de concepções e práticas dos educadores. Esse tipo de mudança dificilmente é alcançada com apenas um processo formativo, com um número limitado de encontros. Assim, defende-se a perspectiva de formação permanente de educadores, partindo da ideia de inacabamento do ser humano, do reconhecimento da necessidade de transformação das realidades, tanto dos educandos quanto da realidade de trabalho dos docentes.

Ainda, é necessário investigar em que medida os elementos teóricos e metodológicos sinalizados pelos pesquisadores contribuem para superação dos desafios apontados por este estudo e de outros desafios na formação de educadores dos anos iniciais. 


\title{
Possibilities and challenges for the continuing education of early years educators: a literature review
}

\begin{abstract}
The research presented here aimed to investigate theoretical and methodological elements that contribute to the construction of educational processes of educators working in the early years of elementary school. It is based on the understanding that science teaching in the early years faces some challenges and that the offer of permanent education, based on the references of the Freire-STS articulation, is an alternative to the overcome these. Thus, an investigation was made in the minutes of the last five editions of ENPEC and SNEF seeking to identify research that dealt with training processes developed with teachers of the early years of elementary school. Sixteen works were selected from the keywords "Science Technology Society" "Paulo Freire" and "Scientific Literacy", which were analyzed according to the Discursive Textual Analysis. The results indicate some possibilities for building formative processes, divided into theoretical and methodological elements and also some challenges that need to be faced by the formators. The results obtained can contribute to the construction of training processes that seek to overcome the challenges encountered in science education in the early years. However, a perspective of permanent formation is defended with a view to overcoming challenges that involve profound changes in the conceptions and pedagogical practice of educators.

KEYWORDS: Teaching Science. Ongoing formation. Initials years. Freire-STS joint.
\end{abstract}




\section{AGRADECIMENTOS}

Agradecemos a CAPES pela bolsa de mestrado concedida.

\section{REFERÊNCIAS}

ABREU, L. S.; BERJARANO, N.; CARVALHO, A. M. P. Professores de Ciências no Ensino Fundamental I como aprendizes: um estudo de caso. In: VIII Encontro Nacional de Pesquisa em Educação em Ciências. 2011, Campinas. Anais... Campinas: 2011.

ARAÚJO, L. B.; MUENCHEN, C. Os Três Momentos Pedagógicos como Estruturantes de Currículos: Algumas Potencialidades. Alexandria: Revista de Educação em Ciência e Tecnologia, v. 11, n. 1, p. 51-69, Florianópolis: maio/2018.

AULER, D. Novos caminhos para a educação CTS: ampliando a participação. In: CTS e educação científica: desafios, tendência e resultados de pesquisa. Org. Auler, D.; Santos, W. L. P. Brasília: Editora Universidade de Brasília, p. 73-97, 2011.

AULER, D.; DELIZOICOV, D. Alfabetização científico-tecnológica para quê? Ensaio: pesquisa em educação em ciências, V. 03, n. 01, jun. 2001.

AULER, D.; DELIZOICOV, D. Educação CTS: articulação entre pressupostos do educador Paulo Freire e referenciais ligados ao movimento CTS. In: Las Relaciones CTS en la Educación Científica. Málaga, Anais..., Espanha:2006.

AULER, D.; DELIZOICOV, D. Investigação de temas CTS no contexto do pensamento latino-americano. Linhas Críticas, vol. 21, núm. 45, maio-agosto, 2015, pp. 275-296.

BRASIL. Ministério da Educação. Secretaria de Educação Básica. Base Nacional Comum Curricular. Brasília: MEC, 2017.

BRASIL. Secretaria de Educação Fundamental. Parâmetros Curriculares Nacionais: Ciências Naturais/Secretaria de Educação Fundamental. Brasília: MEC, 1997.

CARVALHO, L. S.; MARTINS, A. F. História da Ciência na Formação de Professores da Séries Iniciais: uma proposta com quadrinhos. In: VII Encontro Nacional de Pesquisa em Educação em Ciências. 2009, Florianópolis. Anais... Florianópolis: 2009.

CENTA, F. G. "Arroio Cadena: cartão postal de Santa Maria?": possibilidades e desafios em uma reorientação curricular na perspectiva da Abordagem Temática. Dissertação de Mestrado - Universidade Federal de Santa Maria, Centro de Ciências Naturais e Exatas. Santa Maria: 2015.

CENTA, F. G.; MUENCHEN, C. O despertar para uma cultura de participação no trabalho com um Tema Gerador. Alexandria: revista de educação em Ciência e Tecnologia, v. 9, n. 1, p. 263-291, maio/2016. 
DELIZOICOV, D. Conhecimento, Tensões e Transições. Tese de Doutorado Universidade de São Paulo, Faculdade de Educação. São Paulo:1991.

DELIZOICOV, D.; ANGOTTI, J. A. P.; PERNAMBUCO, M. M. Ensino de Ciências: fundamentos e métodos. 4. Ed. São Paulo: Cortez, 2011.

DEMO, P. Educar pela pesquisa. Campinas: Editora Autores Associados, 1996.

EIRAS, W. C. S.; MENEZES, P. H. D. Capacitação e prática docente no ensino de Ciências nos anos iniciais do Ensino Fundamental: uma relação necessária. In: X Encontro Nacional de Pesquisa em Educação em Ciências. 2015, Águas de Lindóia. Anais... Águas de Lindóia: 2015.

FREIRE, P. Pedagogia do Oprimido. Rio de Janeiro: Editora Paz e Terra, 2005.

FREIRE, P. Pedagogia da Autonomia: saberes necessários à prática educativa. São Paulo: Paz e Terra, 2014.

KRASILCHIK, M. Reformas e Realidade: o caso do ensino das ciências. São Paulo em Perspectiva. vol. 14, n. 1, p. 85-93, 2000.

LIMA, M. E. C. C.; MAUÉS, E. Uma releitura do papel da professora das séries iniciais no desenvolvimento e aprendizagem de ciências das crianças. Ensaio: pesquisa em educação em ciências, Belo Horizonte, vol. 8, no 2, 161-175, 2006.

MARQUES, S. G.; HUNSCHE, S. Ciências nos Anos Iniciais: que ensino é esse? In: XI Encontro Nacional de Pesquisa em Educação em Ciências. 2017, Florianópolis. Anais... Florianópolis: 2017.

MORAES, R.; GALIAZZI, M. C. Análise Textual Discursiva. 2. ed. rev. Ijuí: UNIJUÍ, 2007.

MUENCHEN, C.; DELIZOICOV, D. A construção de um processo didáticopedagógico dialógico: aspectos epistemológicos. Ensaio: pesquisa em educação em ciências, v. 14, n. 3, p. 199-215. Belo Horizonte, 2012.

PIERSON, A. H. C. O cotidiano e a busca do sentido para o ensino de Física. Tese (Doutorado em Educação) - Faculdade de Educação, Universidade de São Paulo, São Paulo, 1997.

ROSA, C. W.; PEREZ, C. A. S.; DRUM, C. Ensino de Física nas Séries Iniciais: concepções da prática docente. Investigações em Ensino de Ciências, v. 12, n. 3, p.357-368, 2007.

SANTIAGO, M. E.; BATISTA NETO, J. Formação de professores em Paulo Freire: uma filosofia como jeito de ser estar e fazer pedagógicos. Revista e-Curriculum, v. 7, n. 3, dezembro/2011, pp. 1-19.

SCHNEIDER, T.M.; CENTA, F.G.; ILHA, G.C.; MAGOGA, T.; MUENCHEN, C. no I, VIII e IX ENPECs. In: XV Encontro de Pesquisa em Ensino de Física (XV EPEF), 2014, Maresias/SP. Atas..., 2014. 
SILVA, A. F. G. A construção do currículo na perspectiva popular crítica: das falas significativas às práticas contextualizadas. Tese de Doutorado - Pontifícia Universidade Católica de São Paulo. São Paulo: 2004.

VIECHENESKI, J. P.; CARLETTO, M. Por que e para quê ensinar ciências para crianças. Revista Brasileira de Ensino de Ciência e Tecnologia. v. 6, n. 2, p. 213227, maio-agosto 2013.

VIECHENESKI, J. P.; LORENZETTI, L.; CARLETTO, M. R. Alfabetização Científica nos anos iniciais: uma análise dos trabalhos apresentados nos ENPECs. In: X Encontro Nacional de Pesquisa em Educação em Ciências. 2015, Águas de Lindóia. Anais... Águas de Lindóia: 2015.

Recebido: 15 ago. 2019

Aprovado: 04 out. 2019

DOI: $10.3895 /$ actio.v4n3.10537

Como citar:

MARQUES, S. G.; MUENCHEN, C. Possibilidades e desafios para a formação permanente de educadores dos anos iniciais: uma revisão de literatura. ACTIO, Curitiba, v. 4, n. 3, p. 411-429, set./dez. 2019. Disponível em: https://periodicos.utfpr.edu.br/actio. Acesso em: XXX

Correspondência:

Sabrina Gonçalves Marques

Rua Dom Pedro II, 96. 96570-000, Centro, Caçapava do Sul, Rio Grande do Sul, Brasil.

Direito autoral: Este artigo está licenciado sob os termos da Licença Creative Commons-Atribuição 4.0

Internacional.

(c) (i) 